\title{
ARTIGO \\ REPERTÓRIO DE AÇÕES E CONFERÊNCIAS EDUCACIONAIS: INTELECTUAIS E PROJETOS EM DISPUTA PELA MODERNIDADE EDUCACIONAL (BRASIL, ANOS DE 1920)
}

SOLANGE APARECIDA DE OLIVEIRA HOELLER ${ }^{1}$

ORCID: https://orcid.org/0000-0003-3580-8440

MARIA DAS DORES DAROS ${ }^{2}$

ORCID: https://orcid.org/0000-0003-3473-3096

\begin{abstract}
RESUMO: Este texto constitui uma abordagem na área da História da Educação, tendo como fio condutor a história intelectual e cultural, procurando compreender cinco conferências educacionais ocorridas no Brasil nos anos de 1920: Conferência Interestadual do Ensino Primário (Rio de Janeiro, 1921); Congresso de Ensino Primário e Normal (Paraná, 1926); Primeiro Congresso de Instrução Primária (Minas Gerais, 1927); Primeira Conferência Estadual do Ensino Primário (Santa Catarina, 1927); Primeira Conferência Nacional de Educação, promovida por intermédio da ABE (Curitiba, 1927). A proposta considera as conferências educacionais como integrantes de um repertório compartilhado por seis intelectuais: Orestes de Oliveira Guimarães, Antonio de Sampaio Dória, Lysimaco Ferreira da Costa, Antonio de Arruda Carneiro Leão, Francisco Luís da Silva Campos e Manoel Bergström Lourenço Filho, compreendidos como representantes de projetos em disputa pela modernidade educacional, com destaque para a expansão, gratuidade e obrigatoriedade do ensino primário. Apresenta-se a seguinte questão-problema: como pensar as conferências educacionais como integrantes de um repertório que mobilizou sujeitos - intelectuais - em defesa e disputa de concepções e projetos, no intento de estabelecer em que sentidos e significados a modernidade educacional deveria estar assentada no Brasil dos anos de 1920? O percurso teórico-metodológico e as análises realizadas circundam os conceitos de moderno/modernidade, repertório, intelectuais e representação. Atingir a modernidade educacional, em relação ao Brasil, no período indicado, exigiu articulações e ações que, em tese, garantiriam o pretendido, dentre elas estavam os aspectos da expansão, gratuidade e obrigatoriedade do ensino primário.
\end{abstract}

Palavras-chave: Conferências educacionais, modernidade educacional, ensino primário.

\section{A REPERTOIRE OF ACTIONS AND EDUCATIONAL CONFERENCES: INTELLECTUALS AND PROJECTS IN DISPUTE FOR EDUCATIONAL MODERNITY (1920S BRAZIL)}

\begin{abstract}
This text, in the field of educational history, focuses on intellectual and cultural history to understand five educational conferences held in Brazil in the 1920s - the Interstate Conference on Primary Education (Rio de Janeiro, 1921); the Congress of Primary and Normal [Teacher] Education (Paraná, 1926); the First Congress of Primary Instruction (Minas Gerais, 1927); the First State Conference of Primary Education (Santa Catarina, 1927); and the First National Education Conference, which was promoted by the Brazilian Association of Education (ABE) (Curitiba, 1927). The conferences are
\end{abstract}

\footnotetext{
${ }^{1}$ Instituto Federal Catarinense (IFC). Rio do Sul, SC, Brasil. <solange.hoeller@ifc.edu.br>

${ }^{2}$ Universidade Federal de Santa Catarina. Florianópolis, SC, Brasil.<m.daros@ufsc.br>
} 
considered part of a repertoire shared by five intellectuals: Orestes de Oliveira Guimarães, Antonio de Sampaio Dória, Lysimaco Ferreira da Costa, Antonio de Arruda Carneiro Leão, Francisco Luís da Silva Campos, and Manoel Bergström Lourenço Filho, who are considered representatives of projects in dispute for educational modernity, highlighting the expansion, gratuity, and mandatory features of primary education. The research question is: how can we consider these conferences as part of a repertoire that mobilized intellectuals in defense and dispute of concepts and projects, in an effort to establish the meanings that would guide educational modernity in Brazil in the 1920s? The theoretical methodological approach and analyses involve the concepts of modern and modernity, repertoire, intellectuals, and representation. Reaching educational modernity in Brazil in the period required articulations and actions which, in theory, would guarantee reaching certain goals, such as the expansion of a primary compulsory free education.

Keywords: Educational conferences, educational modernity, primary education.

\section{REPERTORIO DE ACCIONES Y CONFERENCIAS EDUCACIONALES: INTELECTUALES Y DISPUTA DE PROYECTOS POR LA MODERNIDAD EDUCACIONAL (BRASIL, AÑOS 1920)}

RESÚMEN: El hilo conductor de este texto es la historia intelectual y cultural de la educación. Analiza cinco conferencias educacionales que ocurrieron en Brasil en la década de 1920: la Conferencia Interestatal de Enseñanza Primaria (Río de Janeiro, 1921); el Congreso de Enseñanza Primaria y Normal (Paraná, 1926); el Primer Congreso de Instrucción Primária (Minas Gerais, 1927); la Primera Conferencia Estatal de Enseñanza Primaria (Santa Catarina, 1927), y la Primera Conferencia Nacional de Educación, promovida por la $\mathrm{ABE}$ (Curitiba, 1927). Ellas forman parte de un repertorio compartido por seis intelectuales: Orestes de Oliveira Guimarães, Antonio de Sampaio Dória, Lysimaco Ferreira da Costa, Antonio de Arruda Carneiro Leão, Francisco Luís da Silva Campos y Manoel Bergström Lourenço Filho. Ellos son representantes de proyectos en la disputa por la modernidad educacional, donde se destacan la expansión, gratuidad y obligatoriedad de la enseñanza primaria. Se plantea la siguiente cuestión: ¿Cómo pensar dichas conferencias como integrantes de un repertorio que movilizó intelectuales en la defensa y disputa entre concepciones y proyectos para establecer los sentidos y significados sobre los cuales debería basarse la modernidad educacional en el Brasil de los años 1920? La trayectoria teórica y metodológica y los análisis realizados giran alrededor a los conceptos de moderno/modernidad, repertorio, intelectuales y representación. Alcanzar la modernidad educacional, en relación a Brasil, en el período en cuestión exigió acciones y articulaciones que, en tesis, garantizarían lo pretendido. Entre ellas, los aspectos de la expansión, gratuidad y obligatoriedad de la enseñanza primaria.

Palabras clave: Conferencias educacionales, modernidad educacional, enseñanza primaria.

\section{INTRODUÇÃO}

Apresenta-se uma investigação, na perspectiva da história da educação, acerca de projetos em disputa pela modernidade educacional, com centralidade em cinco conferências educacionais, ocorridas no Brasil nos anos de 1920: Conferência Interestadual do Ensino Primário (Rio de Janeiro, 1921); Congresso de Ensino Primário e Normal (Paraná, 1926); Primeiro Congresso de Instrução Primária (Minas Gerais, 1927); Primeira Conferência Estadual do Ensino Primário (Santa Catarina, 1927); Primeira Conferência Nacional de Educação, promovida por intermédio da ABE (Curitiba, 1927). Dos cinco eventos, foram destacados seis intelectuais: Orestes de Oliveira Guimarães, Antonio de Sampaio Dória, Lysimaco Ferreira da Costa, Antonio de Arruda Carneiro Leão, Francisco Luís da Silva Campos e Manoel Bergström Lourenço Filho .

No sentido de tomar as conferências educacionais como possibilidade de investigar os projetos para o Brasil, que assinalavam a educação requerida para a nação, os conceitos de 
moderno/modernidade, repertório, intelectuais e representação deram fluxo ao percurso teóricometodológico trilhado.

Destaca-se como objetivo central: investigar aspectos e elementos que se entrecruzam, na intenção de pensar as conferências educacionais (CIEP-RJ; CEPN-PR; ICIP-MG; ICEEP-SC; ICNEABE) como integrantes de um repertório que mobilizou sujeitos - intelectuais - em defesa e disputa de concepções e projetos educacionais, no intento de estabelecer em que sentidos e significados a modernidade educacional deveria estar assentada. Nesta discussão, apresentar-se-á a expansão, a gratuidade e a obrigatoriedade escolar para o ensino primário como possibilidades de análise para a compreensão da modernidade educacional no Brasil dos anos de 1920.

A expressão conferências educacionais, utilizada neste texto, compreende tanto o que está identificado nas fontes como "conferência" quanto o que traz a nomenclatura de "congresso"; tanto o que tem como adjetivo "instrução primária" quanto "ensino primário ou normal" ou "educação".

Le Goff (1990; 1997, p.2) aborda questões relativas aos conceitos de moderno, modernidade, modernização e modernismo. Sobre o que pode ser correspondente ao moderno ele evidencia o caráter histórico e polissêmico do par antigo/moderno. Informa que esse par se desenvolveu em um contexto equívoco e complexo. Afirma que "[...] cada um dos termos e correspondentes conceitos nem sempre se opuseram um ao outro: 'antigo' pode ser substituído por 'tradicional' e 'moderno', por 'recente' ou 'novo' [...]" e também "[...] porque qualquer um dos dois pode ser acompanhado de conotações laudatórias, pejorativas ou neutras".

Para o autor, esse par - antigo/moderno - e o seu jogo histórico e dialético são gerados entre aquilo que é moderno, onde a consciência da modernidade nasce do sentido de ruptura com o passado. Antigo ainda se desloca para outros comparativos: modernidade, modernização, modernismo (LE GOFF, 1990; 1997).

No Brasil dos anos de 1920, argumentava-se sobre os ideais do moderno/modernidade ao mesmo tempo em que o país procurava equiparar-se com novas técnicas de modernização em diversos setores da sociedade e também discutia, em outras áreas, um movimento modernista. É possível presumir que o que constitui o par antigo/moderno - no Brasil dos anos de 1920 - implica abarcar os sentidos do que ele próprio representava (o moderno como consciência da modernidade), a modernização (como modernas técnicas que respondessem às necessidades do momento histórico), o modernismo (as transformações sugeridas e efetivadas no campo cultural, sobretudo no campo das artes).

Pode-se propor as conferências - composição e proposição - como elementos que compunham o moderno/modernidade nos anos de 1920, uma vez que, também com elas e por meio delas, se pretendia atingir a renovação educacional. Tais espaços se concretizavam, ainda, pelas discussões, debates, embates entre sujeitos que explicitavam suas ideias, concepções e projetos que tinham como alvo o novo, o progresso, ultrapassando os limites do que se tinha como antigo ou tradicional, enfim, atingir a modernidade educacional.

Como representação da modernidade, do novo e do progresso, cada uma das conferências educacionais era anunciada com vivas às iniciativas que a propunha, marcando o evento como símbolo do que se pretendia alcançar para a nação, por meio da educação e cultura do povo brasileiro. A ideia de representação, tomada aqui, se beneficia da perspectiva de Chartier (1990; 1991; 1995; 2001; 2004), que confirma que "[...] toda história, quer se diga econômica, social ou religiosa, exige o estudo dos sistemas de representação e dos atores que eles geram" (CHARTIER, 2004, p. 19). Representação como “[...] esquemas intelectuais, que criam as figuras graças às quais o presente pode adquirir sentido, o outro tornar-se inteligível e o espaço ser decifrado" (CHARTIER, 1990, p. 17).

Das cinco ocorrências tomadas nesta análise, observa-se três iniciativas diferentes em relação a isso. Uma delas representada pelas ações do governo federal (CIEP-RJ); três propostas (CEPN-PR, ICIP-MG, ICEEP-SC) pelos governos estaduais paranaense, mineiro e catarinense, considerando ainda que cada uma apresenta suas singularidades; e outra, (ICNE-ABE), por iniciativa da ABE.

Em diálogo com trabalhos referentes às conferências educacionais, também se reconhece: as questões relativas à infância; os princípios renovadores para a educação; a proximidade de temas tratados; um mesmo organizador ou uma mesma iniciativa para alguma das ocorrências. A proximidade temporal desses eventos tem sua centralidade justificada no contexto dos anos de 1920 e que estes são elementos que, em certa proporção, podem aproximar as conferências no sentido de conteúdo e forma. 
No entanto, a discussão que se apresenta neste texto não se estabelece pela iniciativa de reunir os eventos e se optar por um universo maior de conferências, em relação a outros trabalhos existentes. Propõe-se que as conferências educacionais tomadas podem ser analisadas por sua intersecção no contexto dos anos de 1920, situando-as, a priori, em um repertório que se articulava na tentativa de consolidar propostas ou projetos para a modernidade educacional, que estariam também sintonizadas com a pretendida modernidade para a nação.

Diante disso, as conferências educacionais podem ser pensadas em seu conjunto, ainda que tenham partido de iniciativas distintas, que tenham sido organizadas pelos mesmos sujeitos ou por sujeitos distintos, que apresentem algumas temáticas específicas ou de caráter um tanto semelhante, que tenham ocorrido em espaços geográficos comuns ou diferentes, dentre outros aspectos.

É possível tomar as conferências educacionais em seu conjunto, pois é admissível pensar em um repertório do qual elas faziam parte e que permitia suscitar suas ocorrências e situá-las no contexto da década de 1920. Reunir e analisar essas conferências permite perceber a representação, a força e a projeção que alcançaram ou que se pretendia alcançar por meio delas e, como eventos singulares sob alguns aspectos, não eram isolados ou independentes de outras ocorrências ou ações do repertório compreendido. De modo semelhante, os sujeitos que participavam delas estavam articulados com um contexto maior do que as conferências educacionais, que incluem outras formas de representação, participação e ações nos espaços político e social mais amplos, como procurar-se-á demonstrar em relação ao envolvimento dos intelectuais aqui destacados, com o movimento de reformas educacionais no Brasil.

Tilly propôs o conceito de repertório a partir da década de 1970, a princípio compreendendoo como repertório de ações coletivas com base na teoria de mobilização política, rechaçando explicações economicistas, deterministas e psicossociais da ação coletiva.

Nos anos de 1970 e de 1980 repertório é tratado como "padrões de ação" ou na defesa de que há "um repertório familiar de ações coletivas que estão à disposição das pessoas comuns" num dado período histórico. Mas, coube questionar: "Repertório é comum à época inteira partilhado por todos, ou relativo a atores em particular? (...). Como membros da vida social conhecem, manejam e transformam repertórios?" (TILLY apud ALONSO, 2012, p. 23).

No texto Contentions repertoires in Great Britain, 1758-1835, Tilly (1995, p. 27) (re)significou a expressão como repertório de confronto, ao mesmo tempo em que procurou responder aos questionamentos citados anteriormente: "Como suas contrapartes teatrais, repertório de ação coletiva não significa performances individuais, mas meios de interação entre os pares ou conjuntos maiores de atores. A companhia, e não um indivíduo, mantém um repertório ".

Tilly, McAdam e Tarrow (2009, p. 24), com um refinamento das ideias iniciais de Tilly da década de 1970, argumentam que repertórios "não são simplesmente uma propriedade dos atores em movimento; são uma expressão da interação histórica e atual entre eles e seus opositores".

O repertório dos anos de 1920, no Brasil, foi compreendido por alguns elementos ou ações que se articulam aos sujeitos - intelectuais - em destaque: conferências educacionais; reformas educacionais; ocupação de cargos/funções na área da Educação e na esfera da administração pública; difusão de ideias por meio de impressos ou discursos (teses ou discursos divulgados nas conferências educacionais, artigos em revistas ou imprensa).

Orestes Guimarães, Sampaio Dória, Lysimaco Ferreira da Costa, Carneiro Leão, Francisco Campos e Lourenço Filho foram tomados como atores desse repertório e, pela ressonância de suas ações, pode-se afirmar que foram intelectuais que reivindicaram a modernidade educacional, propondo projetos em consonância com os ideais pretendidos pela nação.

O conceito de intelectual, cunhado a partir das proposições de Sirinelli (1986; 1992; 1998; 2003), pode ser definido por uma geometria variável, porém, baseada em invariantes, sendo possível por duas acepções que não necessariamente estão sempre desvinculadas. Uma propõe o intelectual numa concepção ampla e sociocultural que "[...] engloba os 'criadores' e os 'mediadores' culturais" e "[...] estão abrangidos tanto o jornalista como o escritor, o professor secundário quanto o erudito" e ainda "[...] postam-se uma parte dos estudantes, criadores ou 'mediadores' em potencial, e ainda outras categorias de 'receptores' da cultura”. A segunda definição, de natureza política, mais estreita, é baseada na noção de engajamento do intelectual na vida da cidade (SIRINELLI, 2003, p. 242, 1986). 
Dispensou análises da história das ideias, apoiada na lógica interna dos sistemas de pensamentos, Sirinelli (1986, p. 98) citou Jacques Julliard (1984), lembrando a obviedade: "as ideias não andam nuas pela rua" (JULLIARD apud SIRINELLI, 1986, p. 98). Opôs-se aos trabalhos biográficos, de trajetórias individuais, que não consideram o contexto histórico das biografias como as afinidades, aproximações, escolhas, filiações e outros aspectos do cotidiano, marcados pelas sensibilidades, que permitem compreender "como as ideias vêm aos intelectuais" (SIRINELLI, 2003, p. 256).

Sirinelli (1986, p. 102) afirma ser possível reconstruir itinerários, tomando-se um estudo comparativo dos caminhos percorridos por intelectuais a partir de uma "matriz comum" que pode ser institucional (frequentar a mesma instituição de ensino), política (filiação a um partido político ou adesão a ideologias condutoras de algumas ações comuns) ou outra matriz que promova aproximações ou permita perceber aspectos dos itinerários dos indivíduos inseridos na vida social e coletiva.

\section{REPERTÓRIO, INTELECTUAIS E CONFERÊNCIAS EDUCACIONAIS: AMBIÊNCIA CULTURAL, INTELECTUAL E POLÍTICA}

A compreensão de intelectuais, no contexto dos anos de 1920, busca seus argumentos quanto a atuação dos sujeitos - Orestes de Oliveira Guimarães, Antonio de Sampaio Dória, Lysimaco Ferreira da Costa, Antonio de Arruda Carneiro Leão, Francisco Luís da Silva Campos e Manoel Bergström Lourenço Filho -, compreendia a possibilidade de interferência nos espaços sociais mais amplos e nas transformações requeridas pela via da cultura, tendo na educação e na escola primária um dos seus objetivos.

Esses protagonistas são entendidos como aqueles que apresentam uma trajetória de formação escolar, de atuação profissional e vinculações que permitiam que atuassem em determinadas frentes, nas quais a cultura e a educação podem ser compreendidas como elementos para as reformulações pretendidas, a exemplo dos investimentos relacionados às conferências educacionais. Esses intelectuais que participaram das conferências educacionais não tinham suas ações isoladas ou exclusivas a esses espaços. As conferências educacionais representam um dos lugares e ações - inseridas em um repertório mais amplo - que eram compartilhados por eles.

A discussão de ações e lugares compartilhados não quer afirmar que todos os sujeitos conviveram ou participaram simultânea ou conjuntamente de todas as ocorrências expostas, embora, em certos casos, isso seja correspondente. Há intelectuais que estiveram presentes ou participaram das mesmas conferências, ações ou ocuparam lugares comuns.

As experiências compartilhadas, como se pode acompanhar nos quadros que seguirão, não podem ser tomadas como bloco homogêneo. Antes devem ser percebidas por suas aproximações e singularidades que, entre essas duas perspectivas - aproximações e singularidades -, confluíram para que os intelectuais estivessem envolvidos com as conferências educacionais e inseridos em um repertório que convergia para um projeto de modernidade educacional para o Brasil. 


\section{Quadro $^{3} 1$ - Dados biográficos escolar dos intelectuais: cidade, estado e ano de nascimento/falecimento e formação.}

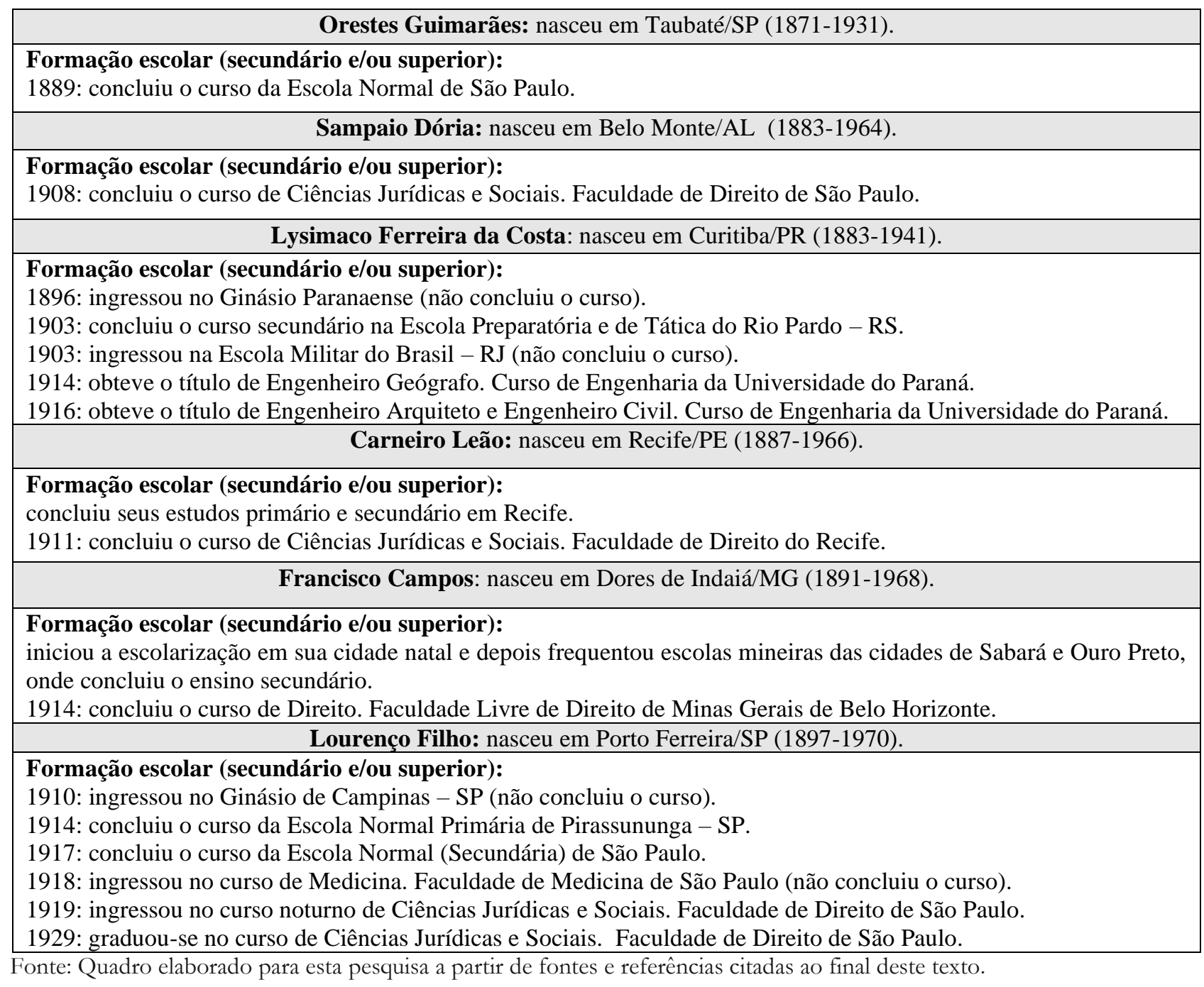

Dos seis intelectuais, nem todos gozavam de recursos econômicos favoráveis, porém, o que os aproxima, pode ser reconhecido pelo valor cultural preservado pelo meio familiar (de origem) que, com maior ou menor condição econômica, permitiu que a educação tivesse lugar privilegiado.

Nem todos fazem parte da chamada "geração nascida com a República", no sentido de terem nascido após o ano de 1889, entretanto, a proximidade entre eles pode ser assinalada pela identificação de que todos tiveram parte ou todo o seu percurso de formação e, principalmente, de atuação profissional, no contexto do Brasil republicano.

Destaca-se a aproximação desses intelectuais pelas experiências comuns, delineadas pela ambiência social, cultura e política dos anos de 1920, que os colocava em condição de participarem e de proporem nos espaços das conferências educacionais, percebendo-se, ainda, outros elementos que compunham o repertório do qual eles faziam parte.

\footnotetext{
${ }^{3}$ Os quadros (1 e 2) representam a possibilidade de visualização de alguns traços da trajetória escolar e profissional dos intelectuais, não significando um mapeamento de todos os aspectos que envolveram sua intensa atuação. Alguns períodos, relativos a certas ações, não foram localizados.
} 


\section{Quadro 2-Dados biográficos dos intelectuais: atuação docente, gestão em instituições educativas, cargos públicos.}

\begin{tabular}{|c|}
\hline Orestes Guimarães \\
\hline $\begin{array}{l}\text { Atuação na docência ou em gestão de instituições educativas: } \\
\text { 1896-1906: professor do ensino primário de escola isolada do Estado de São Paulo e diretor de grupos escolares em São } \\
\text { Paulo. } \\
\text { 1906-1909: diretor do Colégio Municipal de Joinville - SC. } \\
\text { 1909-1910: diretor do Grupo Escolar do Braz - SP. } \\
\text { Ocupação de cargos/funções na esfera da administração pública: } \\
\text { 1911-1918: inspetor-geral do Ensino do Estado de Santa Catarina. } \\
\text { 1918-1931: inspetor federal das Escolas Subvencionadas pela União, no Estado de Santa Catarina. }\end{array}$ \\
\hline Sampaio Dória \\
\hline $\begin{array}{l}\text { Atuação na docência ou em gestão de instituições educativas: } \\
\text { Professor no Ginásio Macedo Soares e, depois de formado no Curso Normal, foi vice-diretor. } \\
\text { Professor na Escola de Comércio Álvares Penteado. } \\
\text { 1914-1925: professor catedrático de Psicologia, Pedagogia e Educação Cívica. Escola Normal Secundária de São Paulo. } \\
\text { 1920: professor nomeado (substituto) para as Disciplinas de Direito Público, Direito Constitucional, Direito Internacional } \\
\text { Público e Privado. Faculdade de Direito de São Paulo. } \\
\text { 1925: nomeado livre-docente. Faculdade de Direito de São Paulo. } \\
\text { 1926-1939: professor concursado da cadeira de Direito Constitucional. Faculdade de Direito de São Paulo. } \\
\text { 1926: participou da fundação e dirigiu o Lyceu Nacional Rio Branco. } \\
\text { 1930-1945: tornou-se proprietário do Colégio (Lyceu) Rio Branco. } \\
\text { 1939: aposentado, compulsoriamente, da Faculdade de Direito de São Paulo. } \\
\text { 1941: reintegrado à Faculdade de Direito de São Paulo. } \\
\text { 1964: declarado Professor Emérito da Faculdade de Direito de São Paulo } \\
\text { Ocupação de cargos/funções na esfera da administração pública: } \\
\text { 1920-1921:diretor da Instrução Pública de São Paulo. } \\
\text { 1934: nomeado 1º procurador-geral do Superior Tribunal Eleitoral e Consultor Jurídico da Secretaria de Educação de São } \\
\text { Paulo. } \\
\text { 1945: designado juiz do Supremo Tribunal Eleitoral. } \\
\text { 1945: nomeado, após a queda do Estado Novo, Ministro da Justiça dos Negócios do Interior. }\end{array}$ \\
\hline Lysimaco Ferreira da Costa \\
\hline $\begin{array}{l}\text { Atuação na docência ou em gestão de instituições educativas: } \\
\text { 1906: professor catedrático de Física e Química no Ginásio Paranaense. } \\
\text { 1915: nomeado para reger a cadeira de Química Mineral e Orgânica. Curso de Engenharia Civil. } \\
\text { 1918: professor de Física Agrícola na Escola Agronômica do Paraná. } \\
\text { 1918: diretor da Escola Agronômica do Paraná. } \\
\text { 1920-1925: diretor do Ginásio Paranaense e da Escola Normal de Curitiba. } \\
\text { 1920: professor de Pedagogia. Escola Normal de Curitiba. } \\
\text { 1930: retornou à docência no Ginásio Paranaense e na Faculdade de Engenharia do Paraná. } \\
\text { Ocupação de cargos/funções na esfera da administração pública: } \\
\text { 1925-1928: inspetor-geral do Ensino do Estado do Paraná. } \\
\text { 1928-1930: secretário da Fazenda do Estado do Paraná. }\end{array}$ \\
\hline Carneiro Leão \\
\hline $\begin{array}{l}\text { Atuação na docência ou em gestão de instituições educativas: } \\
\text { 1911: professor de Filosofia na Universidade do Recife. } \\
\text { Professor no Colégio Pedro II do Rio de Janeiro. } \\
\text { Professor na Universidade do Rio de Janeiro. } \\
\text { 1945-1957: professor na cadeira de Administração Escolar da Faculdade Nacional de Filosofia da Universidade do Brasil. } \\
\text { 1945-1957: diretor (decano) da Faculdade Nacional de Filosofia da Universidade do Brasil. Professor emérito. } \\
\text { Ocupação de cargos/funções na esfera da administração pública: } \\
\text { 1922-1926: diretor-geral da Instrução Pública do Distrito Federal (Rio de Janeiro). } \\
\text { 1928-1930: secretário da Justiça e Negócios Interiores de Pernambuco. } \\
\text { 1931-1933: diretor da Escola Normal de Artes e Ofícios Wenceslau Braz e diretor do Ministério da Agricultura, Indústria } \\
\text { e Comércio. } \\
\text { 1934: diretor do Instituto de Pesquisas Educacionais do Distrito Federal. } \\
\text { Criou e dirigiu o Centro de Pesquisas Pedagógicas da Universidade do Brasil. }\end{array}$ \\
\hline Campos \\
\hline
\end{tabular}


1916: aprovado professor em concurso nas Disciplinas de Economia Política, Ciências das Finanças, Direito Administrativo.

1918: aprovado professor substituto de Filosofia do Direito e Direito Romano da Faculdade de Direito de Belo

Horizonte.

1932: professor catedrático de Filosofia do Direito na Faculdade Nacional de Direito do Rio de Janeiro.

Ocupação de cargos/funções na esfera da administração pública:

1926-1930: secretário de Estado do Interior, Justiça e Educação de Minas Gerais.

1930: assumiu o Ministério de Educação e Saúde Pública.

1933: consultor-geral da República, em caráter interino.

1935-1937: secretário da Educação do Distrito Federal (Rio de Janeiro).

1937-1942: assumiu o Ministério da Justiça.

\section{Lourenço Filho}

Atuação na docência ou em gestão de instituições educativas:

1915: professor primário. Grupo Escolar de Porto Ferreira - SP.

1920: professor (substituto) de Psicologia, Pedagogia e Educação Cívica. Escola Normal Primária (anexa à Escola Normal Secundária de São Paulo).

1921: nomeado professor de Psicologia e Pedagogia e regente de prática pedagógica. Escola Normal de Piracicaba (SP).

1925-1930: professor de Psicologia e Pedagogia. Escola Normal de São Paulo.

1926: participou da fundação, organização e direção do curso primário do Lyceu Rio Branco.

1931: nomeado para a $3^{a}$ cadeira do curso de aperfeiçoamento. Instituto Pedagógico de São Paulo.

1932-1937: organização e direção do Instituto de Educação do Distrito Federal.

1932-1938: professor de Psicologia Educacional. Instituto de Educação do Distrito Federal.

1935: professor nomeado para a disciplina de Psicologia Educacional. Escola de Educação da Universidade do Distrito

Federal (UDF).

1938: vice-reitor da UDF.

1939: reitor da UDF.

1939: professor catedrático de Psicologia Educacional da Faculdade de Nacional de Filosofia. Universidade do Brasil.

1957: recebeu o título de Professor Emérito da Faculdade Nacional de Filosofia da Universidade do Brasil.

Ocupação de cargos/funções na esfera da administração pública

1922-1923: diretor-geral da Instrução Pública do Ceará.

1930-1931: nomeado diretor-geral da Instrução Pública do Estado de São Paulo

1931: chefe de gabinete do Ministro da Educação e Saúde - Francisco Campos - e organizador dos planos da Faculdade

de Educação Ciências e Letras.

1935: direção temporária do Instituto de Pesquisas Educacionais do Distrito Federal.

1938-1946: organização e direção do INEP.

1947-1951: direção do Departamento Nacional de Educação.

Fonte: Quadro elaborado para esta pesquisa a partir de fontes e referências citadas ao final deste texto.

As notas biográficas levam a considerar que se tratava de intelectuais que perpassaram as décadas de 1910 e 1920 - alguns para além desses períodos -, atuando no campo educacional, em nível regional, nos seus estados, ou em nível nacional, e que possuíam articulações com as áreas política, educacional e cultural, alguns deles dentro e fora do país.

Todavia, vale destacar também que todos estiveram envolvidos, nos anos de 1920, com o repertório demarcado pelos elementos aqui sinalizados: conferências educacionais, reformas educativas, ocupação de cargos/ funções na área da Educação e da esfera da administração pública e difusão de ideias por meio de impressos ou discursos.

Ainda como traços comuns de suas trajetórias, percebe-se, reservadas as particularidades de cada caso, que esses sujeitos que estavam à frente ou participavam das conferências educacionais eram os mesmos que, junto a outros: ocupavam cargos na esfera da administração pública federal ou dos estados; participavam na imprensa jornalística ou como autores; redigiam pareceres acerca de temáticas políticas ou relacionadas à educação; organizavam coleções de obras didáticas ou compareciam no circuito literário e cultural do país, publicando suas ideias, proferindo discursos e conferências; mantinham articulação com o governo dos seus estados, com o governo federal, com entidades civis ou organizações - associações, ligas, academias, etc - de atuação ou projeção nacional.

Pode-se citar que acumularam ou perpassaram atividades em instâncias distintas: alguns foram políticos (com filiação partidária), juristas, poetas, escritores, exerceram atividades em jornais.

Todos foram professores e exerceram funções públicas e administrativas ligadas à educação - foram inspetores ou diretores da instrução pública em estados brasileiros ou na capital federal -, estiveram envolvidos em movimentos reformistas ou em movimentos que pretendiam a renovação 
educacional, em âmbito estadual ou federal e participaram de conferências educacionais, compondo o que aqui se assinala como integrantes de um repertório.

Nessa perspectiva, suas propostas no interior das conferência não partiam de posicionamento isolado, mas estavam marcadas por suas vinculações, conexões e seus deslocamentos construídos no interior de um repertório que abarcava diversas ações, elementos e sujeitos.

Quanto às cinco conferências educacionais investigadas e aos intelectuais destacados, Orestes Guimarães teve maior participação, em termos de presença. Sua atuação na CIEP-RJ foi intensa. Como $1^{\circ}$ secretário, esteve à frente da Conferência por decisão do governo federal. Participou da comissão preparatória e das nove sessões de preparação do evento, em todas as quatorze sessões ordinárias e na de encerramento (BRASIL, 1922). Figurou à frente da elaboração do regimento interno e da organização da ICEEP-SC e, no ano de 1927, integrou a comissão organizadora do evento. Foi $1^{\circ}$ secretário (na $1^{a}$ sessão preparatória) e propôs tese sobre trabalhos manuais. No mesmo ano, representou, como delegado, o estado de Santa Catarina na ICNE-ABE e foi presidente da $2^{\mathrm{a}}$ comissão de análise responsável pelas propostas relacionadas ao ensino primário, apresentando a mesma tese que havia exposto na ICEEP-SC.

Sampaio Dória compareceu à CIEP-RJ como representante da Liga Nacionalista de São Paulo e, como não fez parte da comissão de preparação do evento, esteve presente somente nas sessões ordinárias. Foi o participante que mais discursos proferiu (quatro) e compôs a mesma comissão de análise de Orestes Guimarães, apresentando memória ${ }^{4}$ e contramemória ${ }^{5}$, que podem ser entendidas a partir de reclames feitos, como se verá. Também representou Lourenço Filho por meio do Plano Geral de Prática Pedagógica, que foi realizado na Escola Normal de Piracicaba ${ }^{6}$, da qual Lourenço Filho era mentor e professor.

Carneiro Leão fez parte, juntamente com Orestes Guimarães, da comissão organizadora da CIEP-RJ. Indicado como representante do Governo Federal, junto às comissões permanentes, esteve presente em 22 das 25 sessões que ocorreram. Apresentou tese sobre a organização e os fins do Conselho de Educação Nacional, e foi o relator da $5^{a}$ comissão de análise, encarregada de avaliar esta temática.

Do mesmo modo que Carneiro Leão, o envolvimento de Francisco Campos se deu somente em uma conferência. No ICIP-MG esteve à frente da comissão preparatória e de organização, foi o presidente do evento e proferiu discurso de abertura.

Lysimaco Ferreira da Costa tem seu nome ligado a três conferências. Foi organizador do CEPN-PR e da ICNE-ABE e proferiu discursos nas sessões de abertura dessas ocorrências. Para o CEPN-PR, Lysimaco foi indicado como vice-presidente, mas assumiu, em praticamente todo o certame, o cargo de presidente - em substituição a Caetano Munhoz da Rocha, governador do estado, e discursou na sessão de encerramento. $\mathrm{Na}$ ICNE-ABE, foi organizador e integrou a $3^{a}$ comissão, com o encargo de avaliar "temas gerais". Na seção marcada com o título de convidados, no Regimento Interno da ICEEPSC (SANTA CATHARINA, 1927a), seu nome figurava como o primeiro da lista de pessoas, especialmente convidadas, porém, não compareceu, mas enviou mensagens de congratulações e designou representante.

Considera-se a participação de Lourenço Filho em duas conferências. Na CIEP-RJ ele não compareceu, mas suas ideias circularam por meio da memória apresentada por Sampaio Dória. Compartilhou, presencialmente, do espaço da ICNE-ABE com Lysimaco Ferreira da Costa e Orestes Guimarães.

Os intelectuais, por meio dos referenciais ${ }^{7}$ citados, são considerados atores de ações que compõem o repertório, situados como participantes de uma geração que tem parte da sua formação escolar e atuação profissional no período republicano, cujos itinerários construídos e vivenciados os

\footnotetext{
${ }^{4}$ Memória: o termo é utilizado para expressar as proposições dos participantes da CIEP-RJ e que eram originárias das seis teses que foram tratadas nesse evento.

${ }^{5}$ Contramemória: termo cunhado por Sampaio Dória - registrado nos Anais -, rebatendo os comentários feitos acerca do que apresentou em sua memória.

${ }^{6}$ Ruy Lourenço Filho (apud LOURENÇO FILHO, 2001, p. 5) registra que seu pai (Manoel B. Lourenço Filho) levou “o documento a seu mestre e professor Antonio de Sampaio Dória, que iria representar a Liga Nacionalista de São Paulo, na CIEP-RJ. Sampaio Dória apresentou sua memória sobre a educação nacional e, em anexo, o plano elaborado por Lourenço Filho. No dia seguinte ao da conferência, o professor Lourenço Filho tornou-se um nome nacional".

${ }^{7}$ Sirinelli (1986; 1990; 1992; 1998; 2003); Tilly (1976; 1993. 1996; 2004) e McAdam, Tarrrow, Tilly (2009).
} 
colocaram em condições de pensar, representar ou propor nos espaços das conferências. Também são compreendidos pelo engajamento político na vida da sociedade, por se colocarem como porta-vozes do povo, denunciando os problemas e propondo soluções ou possibilidades de intervenção na área educacional, como também no espaço social mais amplo.

\section{MODERNIDADE EDUCACIONAL: EXPANSÃO, GRATUIDADE E OBRIGATORIEDADE PARA O ENSINO PRIMÁRIO}

Tratar dos mobilizadores das conferências, implica avaliá-las pelo seu caráter mais amplo e que suas manifestações se encaminharam, a priori, no sentido de tratar de questões relacionadas à nação, por meio da cultura e da educação - considerando-se os ideais renovadores requeridos - inseridas no contexto dos anos de 1920, na perspectiva de levar o Brasil aos rumos da modernidade.

Tendo-se em conta a relevância de trato ao ensino primário como um dos aspectos preponderantes para efetivar projetos para a nação, apresenta-se a expansão, a gratuidade e a obrigatoriedade desse nível de ensino como possibilidade de garantir a identidade da nação e a modernidade educacional reclamadas.

Expansão, gratuidade e obrigatoriedade do ensino primário deveriam estar entre os pontos destacados da pauta, considerando a superação dos atrasos apontados, como aspectos do novo e do atual, em suma, como representativos da modernidade educacional.

Sem escolas suficientes - expansão -, sem a gratuidade das mesmas e sem a obrigatoriedade de frequentá-las, como pôr em execução projetos para a modernidade da nação por meio da educação? Como instruir, no sentido de alfabetizar, ou como educar na perspectiva de modelar novas condutas do cidadão bom e útil à nação, pautadas na cultura brasileira e em elementos nacionais, sem escolas e sem a imposição às crianças de frequentá-las? De nada valeria propor para a área educacional se não tivessem escolas em proporção suficiente ou se, as tendo, as crianças não as frequentassem.

Nessas argumentações, direta ou indiretamente, as conferências educacionais traziam à tona tais aspectos, como foi o caso da aparteada tese "Diffusão do ensino primário. Fórmula para a União auxiliar a diffusão desse ensino; obrigatoriedade relativa do ensino primário; suas condições" pela $1^{\text {a }}$ comissão da CIEP-RJ.

As críticas mais contundentes foram as de Sampaio Dória. Este iniciou reclamando a não apreciação da sua memória e, após, procedeu com a crítica, ponto a ponto, das conclusões apresentadas. Indagou por que deveria a União ficar encarregada somente da subvenção e argumentava: "acaso a installação directa de escolas federaes, dentro das condições por nós indicadas na 'Memória' que apresentamos, attenta contra á grandeza da Patria?” (BRASIL, 1922, p. 99-100).

Outros também se pronunciaram - dentre eles Carneiro Leão e Orestes Guimarães - sobre as conclusões emitidas, todavia, o fizeram de modo mais brando e alguns até com elogios aos trabalhos realizados. Ainda assim, ocorreram diversas emendas que, por vezes, localizavam os participantes consonantes em alguns pontos e discordantes em outros.

Sampaio Dória apresentou uma emenda (n. $\left.{ }^{\circ} 4\right)$ contrapondo alguns pontos apresentados pela Comissão organizadora do CIEP-RJ, propondo que fosse atendido nos seguintes termos: "É gratuita e obrigatoria a frequência escolar ás crianças de sete a 14 annos [...]" e ficavam exoneradas dessa obrigação:

a) as crianças que residirem além de dous kilometros da escola, ou si não houver vaga nas escolas existentes até esta distancia; b) as incapazes ou atacadas de molestia contagiosas ou repulsivas; c) os indigentes, emquanto o Governo não lhes fornecer e vestuario indispensavel á decencia e á hygiene; d) os que receberem, em casa, ou em escolas particulares, instrucção identica a dada nas escolas publicas primarias (BRASIL, 1922, p. 107).

A emenda n. ${ }^{\circ}$ 4, de Sampaio Dória, foi posta em votação e o autor se posicionou contrário às colocações que consideravam o que ele solicitava com merecimento, mas que não poderia o país, naquele momento, decretar tal medida com a amplitude que se desejava. Rebateu, dizendo não parecerem

\footnotetext{
8 As citações manterão a ortografia e gramática como encontradas nas fontes pesquisadas.
} 
aceitáveis as razões aduzidas pela comissão. A emenda foi posta em votação e foi rejeitada, "contra os votos dos Srs. Sampaio Dória, Orestes Guimarães, Americo Motta, D. Esther de Mello e D. Maria Reis Santos" (BRASIL, 1922, p. 120).

Se no caso acima, Sampaio Dória e Orestes Guimarães estavam de acordo, na votação da emenda do representante do estado de São Paulo, eles e Freitas Valle ${ }^{9}$ - acerca do percentual de subvenção da União para a expansão do ensino primário - estiveram em lados opostos: Sampaio Dória no grupo a favor; Orestes Guimarães, juntamente com Carneiro Leão e outros, votaram contra. A emenda foi aprovada por doze votos a dez (BRASIL, 1922, p. 121).

Quanto à emenda proposta por Orestes Guimarães, consta que foi aprovada, porém, Sampaio Dória declarou ter votado a favor, mas com restrições quanto à fiscalização do ensino (BRASIL, 1922, p. 118). Sampaio Dória, retomando o assunto na nona sessão ordinária, alegou que "Verificando que não ter sido minha proposta examinada pela $1^{a}$ commissão [...], a minha Memória, reiterei-a, em sessão plena, nos mesmos termos: provimento directo de escolas primarias com inspecção e fiscalização a cargo dos Estados, reiterei-a sob a fórma de emenda". Também era possível, segundo Sampaio Dória, que "a Conferência reconsidere o erro de querer instituir em todo o Brasil, com gostos formidáveis, a dupla inspecção: a federal e a estadual. Que lhe não doam as mãos” (BRASIL, 1922, p. 202).

Sampaio Dória declarou na sexta sessão ordinária do CIEP-RJ que "si podemos, pela votação de sábbado, ajuizar e prever, as medidas que suggerimos, em reforma ou additamento aos pareceres das comissões, serão, sem remedio, rejeitadas. O relator da commissão opinará contra o que não houver sahido de si mesmo", mas, assim mesmo, ele continuaria a "propôr o necessário aos pareceres das commissões em reiteração fiel ás idéas de nossa (sua) memória” (BRASIL, 1922, p. 145).

O parecer final da $1^{a}$ comissão - que pode ser lido como um dos projetos educacionais em disputa para o ensino primário brasileiro, em articulação com o compromisso delegado à União - foi votado e aprovado na sétima sessão ordinária, deliberando, com pequenos ajustes de redação, sobre a obrigatoriedade do ensino:

$1^{a}$ A Conferencia Interestadual de Ensino Primario reconhece a competencia do Congresso Nacional para decretar a obrigatoriedade do ensino; $2^{\circ}$ A actual situação do paiz não comporta a decretação desta medida em caracter absoluto; $3^{\circ}$ Os participantes ou emprezas que possuírem estabelecimento fabris ou industriaes que empregam menores em seu serviço, e os particulares que os empreguem em serviços domesticos ficarão na obrigação de lhes ministrar o ensino das primeiras lettras; $5^{\circ}$ Serão punidos pelo modo que a lei determinar os que infringirem o disposto na conclusão anterior (BRASIL, 1922, p. 153).

O parecer aprovado da primeira tese da CIEP-RJ manteve, em grande proporção, o que a $1^{a}$ comissão havia exposto em sua primeira versão. Também se percebe o tom conciliador mantido, que não estabeleceu a obrigatoriedade do ensino primário de modo absoluto, permitindo que se considerassem as observações feitas acerca das dificuldades orçamentárias ou das condições geográficas do país. Do mesmo modo, não se definiu a faixa etária circunscrita pela obrigatoriedade e nem a duração do curso primário.

Todavia, o parecer final aprovado não foi suficiente para acalmar os ânimos dos presentes na CIEP-RJ. Sampaio Dória novamente tomou a palavra, alegando que a sua tão "tão caluniada reforma" (1920) não só não mutilou, mas havia integrado o aparelho escolar paulista. As críticas, porém, têm se fixado no seu

único ponto vulnerável, o seu pobre calcanhar de Achilles é esta a reducção de gratuidade do ensino primario e da obrigatoriedade de frequencia a dous annos apenas. Não se confunda, porém, reducção do ensino primário com reducção da gratuidade. Pela reforma da instrucção paulista, o ensino primário, ali foi elevado de 6 para 7 annos em 10 escolas; a gratuidade é que foi reduzida a dous annos. No mais, que é quasi tudo, aquella reforma, de que sou o principal autor, realizou uma avançada vertiginosa para o ideal. Si, pois S. Paulo era o modelo da instrução pública entre nós, agora mais que nunca, exceptuada a reducção da gratuidade, é lá que o Brasil

\footnotetext{
${ }^{9}$ Freitas Valle argumentou: "A relatividade da população é variavel; a percentagem a adoptar nas capitaes não póde ser a mesma das cidades do interior, nem a dos lugarejos e infimos nucleos do sertão do paiz. Por outro lado, fazer-se depender a obrigatoriedade da existência de caixas escolares é arriscado, pois estas podem ser insufficientes, e isso retardará a execução da medida" (BRASIL, 1922, p. 121).
} 
terá de buscar o melhor padrão de ensino primario e normal. Si se aventurar por caminhos differentes, fará obra de fancaria (BRASIL, 1922, p. 146).

Situadas no mesmo repertório, as reformas educacionais eram evocadas no interior das conferências e entrecruzavam argumentações relacionadas aos aspectos da expansão, gratuidade e obrigatoriedade escolar, gerando também tensões e debates.

Henrique da Silva Fontes - representante de Santa Catarina na CIEP-RJ - espelhou a reforma de São Paulo com o contexto catarinense, rebatendo as afirmações de Sampaio Dória sobre o que dizia ser uma inovação na reforma paulista. No tocante ao curso primário com duração de sete anos, afirmou que, em Santa Catarina, isso já estava proposto desde 1911 pela reforma inspirada e executada por Orestes Guimarães. Seguiu exaltando a atuação de Orestes e do seu estado, enquanto Sampaio Dória intercortava o discurso, refutando que não havia mencionado "inovação", mas elevado o ensino primário a sete anos; também não havia se referido a Santa Catarina e, tampouco, a Henrique da Silva Fontes, questionando: "Quando e onde me referi a V. Ex.? Não fiz referencias pessoaes" (BRASIL, 1922, p. 155).

Os apartes exigiram que Henrique da Silva Fontes se dirigisse à autoridade máxima da CIEPRJ, observando: "Sr. Presidente, quando na última sessão, eu e outros desejavamos dar apartes ao orador, V. Ex. pediu que não o perturbassemos. Não creio que haja aqui dous pesos e duas medidas. Solicito para mim a applicação da mesma medida". Tendo seu pedido deferido, procedeu citando que Sampaio Dória havia mencionado que ele era defensor de escolas de três ou quatro anos regidas por um só professor, o que não representava suas ideias e nem a realidade catarinense. Novamente, intercalou Sampaio Dória: "Mais uma vez, não fiz referencias pessoaes" (BRASIL, 1922, p. 156).

Mesmo diante do clima, por vezes acalorado, Sampaio Dória prosseguia intervindo, opinando e impondo sua presença. "Corre nesta Conferência ${ }^{10}$, que eu sou partidário do ensino primário reduzido de dous annos, sem mais nada. Nunca preguei tamanho absurdo e heresia tamanha. Pelo contrário, sempre que tenho tido ensejo, me tenho manifestado em sentido opposto" (BRASIL, 1922, p. 182). Sustentou que estava de acordo com os outros participantes quanto a escola primária dever ser destinada às crianças de sete a quatorze anos de idade. Entretanto, essa questão ainda foi alvo de críticas posteriores por Carneiro Leão e Orestes Guimarães, o que pode dar indícios de que a questão não tenha encerrado em clima amistoso.

A atuação de Sampaio Dória na referida reforma foi criticada por Carneiro Leão quando este estava à frente da instrução pública do Distrito Federal (1922-1926). As ações reformistas de Carneiro Leão, no Rio de Janeiro, foram compiladas por ele em 1926, sob o título "O ensino na capital do país" e estão registradas as críticas:

É, pois, improcedente e até perigosa toda campanha que busque fixar em 2, 3 ou 4 anos o curso primário, no Brasil. O próprio São Paulo que, por motivos financeiros, julgou solucionar o problema com a redução do estágio gratuito, voltou atrás, estabelecendo o ensino primário em 6 anos, compreendendo os 2 do curso complementar. (LEÃO apud SILVA, 2006, p. 75).

Carneiro Leão explicitava, no Projeto (n. ${ }^{\circ}$ 238) da sua reforma no Distrito Federal, que o ensino primário seria obrigatório e teria a duração de quatro anos na etapa fundamental e dois anos na etapa complementar, desde que houvesse escola pública ou particular subvencionadas e em condições de receber toda a população escolar de sete a catorze anos, dentro de cada perímetro escolar.

Se Carneiro Leão criticou a Reforma de Sampaio Dória em São Paulo, Silva (2006) observa que a realidade catarinense foi fator que mereceu comentários elogiosos, observando que a organização do ensino em Santa Catarina, dentre outros pontos favoráveis, era composta de "[...] jardim de infância, escola primária e curso complementar de três anos, dando ao ensino popular o prazo de nove anos completos" (LEÃO apud SILVA, 2006, p. 76).

\footnotetext{
${ }^{10}$ Fatos envolvendo Sampaio Dória e a sua reforma foram mencionados pela $1^{\mathrm{a}}$ comissão da CIEP-RJ, observando que, devido às condições financeiras, os estados confrontavam-se com as mais sérias dificuldades para levar as letras a todos os seus filhos. Exemplo disso era o "grande Estado se São Paulo" que se viu diante da necessidade de modificar a sua modelar organização pedagógica (BRASIL, 1922, p. 93-94).
} 
$\mathrm{Na}$ problematização da realidade brasileira, Raul Gomes ${ }^{11}$, em tese na ICNE-ABE, questionou a respeito das atribuições do governo federal e das responsabilidades dos estados acerca da expansão e da obrigatoriedade do ensino primário. O proponente apresentou um amplo relatório estatístico, tanto numa perspectiva geográfica - dos diversos estados brasileiros - quanto histórica, para demonstrar que a obrigatoriedade escolar figurava como "letra morta" na legislação pertinente, pois, apesar de prevista há anos, não havia, até aquele momento, encontrado uma "execução sistemática e perdurável em nenhum estado do Brasil" e questionou:

[...] se o minúsculo Estado de Santa Catarina, numa prova admirável da compreensão e do alcance dos sacrifícios empregados na educação popular, aplicava em 1921 20\% de sua renda na instrução, porque esse Brasil de $1934^{12}$, cujo grau de evolução e progresso conquistado [...] não reservará, para a estupenda e redentora tarefa de incorporação da totalidade da classe de seis anos, a ínfima, a simples porcentagem de $8 \%$ sobre a soma da receita geral? (ASSOCIAÇÃO..., 1927 , p. 572; 583).

Entretanto, pelo reconhecimento dado por alguns - dentre eles Carneiro Leão e Raul Gomes - ao contexto catarinense, porque continha em sua legislação a previsão da obrigatoriedade escolar e até menção de modo elevado pelos investimentos na área educacional, isso não pode ser interpretado como se Santa Catarina tivesse equacionado tais questões. Vale observar que a realidade presente no contexto catarinense, nos anos de 1920, ainda reclamava por inúmeras soluções aos problemas atados à instrução pública. A realidade deixava a desejar em diversos aspectos, incluindo a falta de frequência regular dos alunos às aulas, que minava a questão da obrigatoriedade (HOELLER, 2009).

Participantes da ICEEP-SC, como Orestes Guimarães, assinaram uma petição, destacando o Decreto de 04 de dezembro de 1926 e enfatizando a necessidade de o estado fazer "cumprir rigorosamente os preceitos do alludido decreto em relação á frequencia nas escolas de menores de até 14 annos". Na sequência da petição feita, Orestes Guimarães pronunciou que aprovava a medida da obrigatoriedade e lamentava quanto à "diminuição da matrícula nos $3^{\circ}$ e $4^{\circ}$ annos dos estabelecimentos públicos é (que era) reduzida pelo motivo de approveitamento do trabalho dos menores". Estendeu seus comentários, condenando a reforma paulista promovida por Sampaio Dória, em 1920, que reduziu o ensino primário para dois anos, naquele estado, em 1920 (SANTA CATHARINA, 1927b, p. 105-106 grifos nossos).

O Regulamento da Instrução Pública ${ }^{13}$ - derivado das ações empreendidas por Lourenço Filho na reforma educacional no Ceará ${ }^{14}$ - deliberou sobre questões, em alguns pontos, semelhantes a outras reformas em relação às nomenclaturas ou a determinados aspectos. Entretanto, apesar das semelhanças nos assuntos e nomenclaturas, a compreensão de Lourenço Filho acerca do ensino público no Ceará, representada no Regulamento, difere da de São Paulo, proposta por Sampaio Dória, e se aproxima das defesas de Carneiro Leão e Orestes Guimarães. Sobre a gratuidade e a obrigatoriedade do ensino primário, era prevista no "Art. 36 - São obrigadas a frequência escolar gratuita as crianças analfabetas de 7 a 12 anos de idade" (CEARÁ, 1922). Quanto aos casos isentos e as penalidades, Lourenço Filho considerou de modo bastante similar à Reforma de Sampaio Dória.

Moreno (2003, p. 56) demarca que a obrigatoriedade do ensino primário esteve na pauta de discussão do cenário paranaense ao longo de toda a década de 1920 e, dentre os reformadores ${ }^{15}$, Lysimaco Ferreira da Costa foi o único que oscilou, favoravelmente, quanto à discussão sobre a obrigatoriedade, tanto que uma das teses oficiais do CEPN-PR - evento organizado por Lysimaco - se estabeleceu nos

\footnotetext{
${ }^{11}$ Foi professor, redator do jornal O Estado do Paraná e signatário do Manifesto dos Pioneiros da Educação Nova (1932).

12 O projeto apresentado por Raul Gomes, em 1927, na ICNE-ABE, deveria consumar seus objetivos no ano de 1934. (ASSOCIAÇÃ̂..., 1927).

${ }^{13}$ Este Regulamento consta na Coleção Documentos da Educação Brasileira (VIEIRA; FARIAS, 2006).

14 Andrade (2013) explicita que a publicação da Lei n ${ }^{\circ}$ 73, datada de 18 de setembro de 1837, recomendava que todo pai de família estaria obrigado a matricular seus filhos, com idade acima de dez anos, em escolas públicas ou particulares, para que pudessem aprender as primeiras letras, incorrendo - os que não cumprissem - em multa de seiscentos reis por filho.

${ }_{15}$ Moreno (2003, p. 55) observa que os agentes estatais paranaenses, dentre eles César Pietro Martinez, rejeitavam a ideia da obrigatoriedade do ensino primário. César Pietro Martinez afirmou, em 1923, que a obrigatoriedade não tinha razão de ser e que era necessário investir na eficiência dos professores, observando que "O que precisa o Brasil é de escolas e não da obrigatoriedade porque esta nem poderá ser posta em prática”.
} 
termos que questionavam: há necessidade de se tornar rigorosamente obrigatório o ensino elementar no território paranaense?

Tensões se revelaram também no CEPN-PR em torno das (im)possibilidades de ver contemplada a obrigatoriedade escolar no Paraná ${ }^{16}$. A tese de Segismundo Antunes Netto - lente da Escola Normal e Inspetor Escolar de Ponta Grossa - defendeu a obrigatoriedade do ensino no parecer da comissão de análise, reconhecendo a necessidade de difundir "a luz do alfabeto, tornando obrigatório" no Paraná (PARANÁ, 1926a). Entretanto, a tese provocou, entre os presentes, debates acalorados, conforme registro das atas do evento e do jornal Estado do Paraná. A "these foi relatada pelo professor N. Meira de Angelis. Encetada a discussão proferiu brilhante discurso contra a obrigatoriedade o professor José Cardoso, director do grupo escolar de Jacarezinho” (ANGELIS, 1926, s. p.).

Apesar dos apartes, essa tese e outras duas que tratavam da mesma temática, foram aprovadas, pois se defendeu ${ }^{17}$ que "o ensino obrigatório deve necessariamente formar parte na legislação, e encarnar-se nos costumes dos países que querem viver em toda a plenitude da vida da civilização, do progresso e da grandeza da humanidade". No entanto, se argumentava ${ }^{18}$ que era preciso que "firmemos primeiro as paredes e depois ponhamos o telhado ao gigantesco edifício, para que não passemos mais tarde pelo vexame de vermos ruída por terra a sabia lei da obrigatoriedade do ensino", pois ainda era necessário investir em ampliação de número de escolas, em especial, nas zonas rurais, e no seu aparelhamento técnico (PARANÁ, 1926a).

O evento mineiro - ICIP-MG - foi pensado em articulação com a reforma da instrução pública no Estado de Minas Gerais, autorizada pelo governo estadual, em 1926, cuja responsabilidade, como já destacado, esteve sob Francisco Campos, que convocou o certame para pensar a reforma que implementou em 1927, após a ocorrência.

Das ações derivadas da reforma educacional de 1927, fomentada por Francisco Campos no interior do ICIP-MG, se propôs à expansão de escolas para o estado e se definiu a obrigatoriedade de frequência no ensino primário, em acordo com a faixa etária de sete a quatorze anos de idade, estendendose até os dezesseis anos para os indivíduos que, aos quatorze, não estivessem habilitados nas matérias do curso primário, facultando tal medida, casos semelhantes aos apresentados pelas reformas de Orestes Guimarães (SC), Lourenço Filho (CE) e Carneiro Leão (PE), atribuindo penalidades também aproximadas (MINAS GERAIS, 1926; 1927a; 1927b; 1927c).

O repertório analisado e os intelectuais destacados, tanto as conferências educacionais quanto as reformas educativas, como também as defesas e argumentações dos intelectuais destacados em outras circunstâncias, levam a considerar a necessidade de se propor projetos educacionais que colaborassem com o desejo de progresso e modernidade da educação e da nação brasileira.

Tais projetos deveriam contemplar aspectos que pudessem garantir educação que contribuísse para a formação de cidadãos que estivessem em sintonia com o desejado. A modernidade educacional consistia em ultrapassar a condição existente, rumo ao futuro e ao progresso, sendo necessárias escolas suficientes para atender à demanda; além da ampliação da faixa da população a frequentar o ensino primário - figurando dos sete aos quatorze anos -; deliberando pela gratuidade - às custas do poder público -; e pela obrigatoriedade de frequência da população em idade de escolarização primária.

Os intelectuais, como atores do repertório demarcado nos anos de 1920, não fugiam às discussões e debates que envolviam tais questões, uma vez que o progresso e modernidade, sem o alcance na melhoria educacional, não seria possível. Como formar condutas, por meio da escola primária, sem escolas em proporção suficiente, sem a gratuidade e alcance a toda população e sem a obrigatoriedade de frequência? Sem esses elementos preservados, um projeto de modernidade educacional estaria fadado, $a$ priori, ao fracasso.

\footnotetext{
${ }^{16}$ Souza e Anjos (2013) apresentam que as questões ligadas à obrigatoriedade escolar no Paraná também provêm de longa data. Nas fontes que consultaram, há presença de cinco leis instituindo a obrigatoriedade do ensino nos anos de 1854, 1857, 1874, 1877 e 1883. Referem-se ao Perecer n. 2, relativo à seguinte tese "Obrigatoriedade do ensino no território paranaense", de Segismundo Antunes Netto, apresentada na primeira sessão plena, em 20/12/1926, pela manhã (PARANÁ, 1926).

$1715^{a}$ Tese apresentada: Há necessidade de se tornar rigorosamente obrigatório o ensino primário elementar no território paranaense?, de autoria da professora Maria Luiza Ruth (PARANÁ, 1926a).

$1824^{a}$ Tese apresentada: Há necessidade de se tornar rigorosamente obrigatório o ensino primário elementar no território paranaense?, de autoria de João Rodrigues. (PARANÁ, 1926a).
} 
Todavia, não se quer definir, com as afirmações postas nesta discussão, que as exigências reivindicadas foram plenamente atendidas. Contudo, se pode assegurar que os elementos da expansão tanto do número de escolas quanto da faixa etária a frequentar quanto da gratuidade e da obrigatoriedade do ensino primário -, figuraram na pauta dos debates dos anos de 1920 no Brasil e permitem interpretar certos aspectos da representação de projetos para a modernidade educacional.

\section{CONSIDERAÇÕES FINAIS}

Pode-se afirmar que existe uma tendência à realização de eventos - congressos, comissões, conferências - nos quais sujeitos se reúnem para articular, defender, disputar concepções e formular propostas, com a crença de que possam responder às necessidades no âmbito educacional local, regional e nacional.

As conferências educacionais, tanto nos anos de 1920 como em outras décadas passadas, quanto em momentos mais atuais, representadas pelo movimento da CONAE ${ }^{19}$ (BRASIL, 2014; 2018), podem ser compreendidas como lugares públicos para exposição, explicitação e discussão de projetos educacionais que convergem ou, em certos casos, disputam diferentes proposições.

Reservadas as diferenças do momento histórico atual e da ocorrência de eventos nos anos de 1920, faz-se importante a reflexão sobre realidades históricas diversas acerca de projetos e propostas educativos. Esta reflexão pode auxiliar na compreensão do processo histórico-educacional brasileiro e do que esteve e está em evidência no campo da Educação e de que modo isso pode ser tomado, em certa proporção, como um projeto de nação, uma vez que as conferências educacionais não podem ser compreendidas por uma percepção isolada do contexto maior que representava ou representa a realidade educacional brasileira.

Especificamente, quanto aos eventos analisados neste texto, observa-se que o clima entre afirmação de propostas, confirmação de posicionamentos e exigência da compreensão das pertinências ou não das ideias dos participantes e da busca por demarcação de lugares nas conferências, pode ser atribuído a todas as ocorrências.

Sampaio Dória, na CIEP-RJ, não somente foi aquele que não fugiu aos enfrentamentos como também foi quem, por diversas vezes, suscitou tais confrontos. Pode-se propor que foi o participante mais combativo desse evento e, no sopesar, dos demais aqui analisados. Isso não significa que foi quem impôs com maior efetivação suas propostas. Sua postura tem reflexo do seu perfil de orador eloquente, mas também espelha sua condição no cenário educacional e político daquele momento, que se mostrava, de certo modo, fragilizada por sua reforma mal compreendida - segundo suas afirmações - e sua rápida passagem pela diretoria da instrução pública de São Paulo.

Os outros dois intelectuais - Orestes Guimarães e Carneiro Leão - presentes na CIEP-RJ, naquele momento gozavam de posição mais confortável e prestigiosa no cenário educacional e político - exerciam funções na esfera administrativa do governo federal - e tinham seus lugares assentados no espaço da conferência como organizadores, propositores de teses e relatores de comissões de análises das quais faziam parte. Tais posições dispensavam, em certos casos, a necessidade de requerer um lugar destacado naquele evento e os colocavam mais sintonizados com o que se apresentava nas sessões ordinárias, visto que suas teses já haviam sido previamente discutidas ao longo das nove sessões preparatórias, as quais eles se fizeram presentes em todas.

Trazer para a CIEP-RJ a sua memória, permitia a Sampaio Dória não apenas defender seu projeto educacional para o ensino primário brasileiro e o compromisso delegado à União. Com igual intensidade, por meio dela (memória), pode se justificar e rebater as críticas que recebera em sua reforma, fazendo da conferência um espaço público para defesa das suas ações e para explicitação da incapacidade de compreensão das mesmas, por parte do que nomeava de "boateiros". Deste modo é que a memória

\footnotetext{
${ }^{19}$ Segundo o site do MEC (Ministério da Educação e Cultura): a I Conferência Nacional de Educação (CONAE) pretendeu ser um espaço democrático aberto pelo poder público para que todos pudessem participar do desenvolvimento da educação nacional, com o objetivo de tematizar a educação escolar, da Educação Infantil à Pós-graduação.
} 
era sempre mencionada, em conjunto com os aspectos da reforma que, no ano anterior, havia promovido em São Paulo.

Conforme consta nas fontes, as reformas de Orestes Guimarães (Santa Catarina 1911/1913) e Sampaio Dória (São Paulo - 1920) não foram precedidas por conferências educacionais que as justificassem. Todavia, foram levadas à CIEP-RJ de modo exaltado, fosse por defensores dos propósitos, no caso do primeiro, fosse por seu próprio mentor, no caso do segundo.

As reformas educacionais rememoradas demonstram articulação dessas ações dos intelectuais com os espaços das conferências educacionais, fazendo perceber que ambas - reformas e conferências - participavam do repertório dos anos de 1920, do qual os intelectuais faziam parte. Outrossim, auxiliaram no delineamento de projetos educacionais para o país.

Percebe-se que os princípios da expansão, gratuidade e obrigatoriedade do ensino primário não poderiam ficar à margem das propostas dos anos de 1920, pois eram princípios que, em tese, garantiriam a efetivação dos projetos pautados para a modernidade educacional e, por extensão, para a modernidade da nação.

A escola primária gratuita e obrigatória para a faixa etária de sete a quatorze anos, era tomada como lócus privilegiado para o cultivo dos sentimentos, consciência e identidade nacionais. Ao mesmo tempo, deveria contemplar ideais de uma educação renovada pelos novos meios e novos fins da educação, para a formação do cidadão brasileiro e republicano que a sociedade brasileira exigia para aquele momento, segundo a retórica do período.

O movimento reformista dos anos de 1920, do qual os intelectuais - Orestes Guimarães, Sampaio Dória, Lourenço Filho, Carneiro Leão, Lysimaco Ferreira da Costa e Francisco Campos fizeram parte, é representativo dos assuntos relativos à expansão, gratuidade e obrigatoriedade do ensino primário, assim como as conferências educacionais foram lugares de circulação dessas ideias e fazem perceber que o proposto por eles somava-se às vozes de outros sujeitos naquele momento.

Também se pode inferir que as conferências educacionais, presentes no repertório dos anos de 1920, no Brasil, representam possibilidades de interpretação de projetos para a nação e para a modernidade educacional, por meio das teses debatidas e dos sujeitos que reivindicavam as mudanças requeridas para aquele período, em articulação com outros elementos e ações daquele repertório.

\section{REFERÊNCIAS}

ALONSO, A. Repertório, segundo Charles Tilly: história de um conceito. Sociologia \& Antropologia. v. 02, n. 03, p. 21-41, 2012.

ANDRADE, F. A. A obrigatoriedade da instrução pública na província do Ceará. In: VIDAL, D. G.; SÁ, E. F.; SILVA, V. L. G. (Orgs.). Obrigatoriedade escolar no Brasil. Cuiabá: EduFMT, 2013. p. 47-62.

ANGELIS, N. M. O professor pontagrosense homenageado O Estado do Paraná. Cutitiba , 24 dez. 1926. Curitiba, 1926.

ASSOCIAÇÃO BRASILEIRA DE EDUCAÇÃO. I Conferência Nacional de Educação: Curitiba, 1927a. Publicação organizada por COSTA, M. J. F. F.; SHENA, D.; SCHMIDT, M. A. MEC.

SEDIAE/INEP. IPARDES. Brasília, 1997.

BRASIL. Ministério da Educação e Cultura. Conferência Nacional de Educação, 2018 orientações para as conferências municipais, intermunicipais, estaduais e distrital. Brasília-DF, março de 2018. Disponível em:

$<$ http://conae.mec.gov.br/images/pdf/doc_orientacoes_conferencias.pdf > .Acesso em: 27 abril 2020. 
BRASIL. Annaes da Conferência Interestadual de Ensino Primário. Rio de Janeiro: Emp. Industrial Editora "O Norte", 1922.

BRASIL. Ministério da Educação e Cultura. Documento Referência - CONAE. Brasília, 2014. Disponível em: < http://fne.mec.gov.br/images/pdf/documentoreferenciaconae2014versaofinal.pdf>. Acesso em: 24 abril 2020.

CEARÁ. Regulamento da Instrução Pública do Estado. Ceará, 1922. In. VIEIRA, A. L.; FARIAS, I. M. S. (Orgs.). Documentos de política educacional no Ceará: Império e República. Colaboração: NOGUEIRA, D. L. et al. Brasília: Instituto Nacional de Estudos e Pesquisas Educacionais Anísio Teixeira, 2006. (Col. Documentos da Educação Brasileira), p. 153-159.

CHARTIER, R. A história cultural: entre práticas e representações. Rio de Janeiro: Bertrand, 1990.

CHATIER, R. Cultura escrita, literatura e história. Porto Alegre: Artmed, 2001.

CHATIER, R. O mundo como representação. Estudos Avançados, 5 (11), p. 173-191, 1991.

Disponível em: <http://www.revistas.usp.br/eav/article/view/860>. Acesso em: 18 julho 2020.

CHATIER, R. El mundo como representación: estúdios sobre historia cultural. 2. ed. Barcelona: Gedisa, 1995.

CHATIER, R. Leituras e leitores da França no Antigo Regime. São Paulo: Editora da UNESP, 2004.

HOELLER, S. A. O. Escolarização da infância catarinense: a normatização do ensino público primário (1910-1935). 210 f. Dissertação (Mestrado em Educação). Programa de Pós-Graduação em Educação. Universidade Federal do Paraná, Curitiba, 2009.

HOELLER, S. A. O.; DAROS, M. D. Método de ensino para escola primária: discursos na Primeira Conferência Estadual do Ensino Primário (Santa Catarina, 1927). In: IX CONGRESSO LUSOBRASILEIRO DE HISTÓRIA DA EDUCAÇÃO (COLUBHE): Rituais, Espaços \& Patrimônios Escolares, 2012, Lisboa. Anais... Lisboa: Instituto de Educação da Universidade de Lisboa, 2012. p. 110.

JULLIARD, J. Le facisme em France. Annales Economies, Sociétés, Civilisations, 39 (4), p. 849981, juillet-acoût, 1984.

LE GOFF, J. Antigo/moderno. In: Enciclopédia Einaudi, Lisboa, IN-CM, (reed.), vol.1. MemóriaHistória, 1997. p. 370-392.

LE GOFF, J. História e memória (1924). Trad. Bernardo Leitão et al. Campinas: Editora da UNICAMP, 1990.

LOURENÇO FILHO, M. B. A formação de professores: da Escola Normal à Escola de Educação. (Org.) Ruy Lourenço Filho. Brasília: Instituto Nacional de Estudos e Pesquisas Educacionais, 2001. (Col. Lourenço Filho).

MINAS GERAIS. Lei n. 926. Autoriza a reforma do Ensino Primário no Estado de Minas Gerais. Palácio da Presidência do Estado de Minas Gerais. Uberaba, 1926a.

MINAS GERAIS. Regulamento do Ensino Primario. 15 de outubro de 1927. Aprovado pelo Decreto n. 7.970. Palácio da Presidência do Estado de Minas Gerais. Uberaba, 1927c. 
MINAS GERAIS. Revista do Ensino. Orgam Official da Directoria da Instrucção. Ano III, n. 21, maio e junho. Belo Horizonte, 1927a.

MINAS GERAIS. Revista do Ensino. Orgam Official da Directoria da Instrucção. Ano III, n. 22, agosto e setembro. Belo Horizonte, 1927b.

MORENO, J. C. Inventando a escola, inventando a Nação: discursos e práticas em torno da escolarização paranaense (1920-1928). 140 f. Dissertação (Mestrado em Educação). Programa de Pós-Graduação em Educação. Universidade Federal do Paraná, Cutitiba, 2003.

PARANÁ. Congresso de Ensino Primário e Normal (teses). Acervo: Memorial Lysimaco Ferreira da Costa. Curitiba, 1926a.

PARANÁ. Relatório da Secretaria Geral do Estado do Paraná apresentado ao Exmo. Dr. Caetano Munhoz da Rocha, Presidente do Estado, por Alcidez Munhoz, Secretário Geral do Estado, referente aos serviços do exercício financeiro de 1925-1926. Curityba: Livraria Mundial, França \& Cia. Ltda, 1926b.

RIO DE JANEIRO. Projeto n. 238. Reforma da Instrução Pública do Distrito Federal. Distrito Federal (RJ), 1926. In. SILVA, J. A. P. Carneiro Leão e a proposta de organização da educação popular brasileira no início do século XX. 131 f. Dissertação (Mestrado em Educação). Programa de Pós-Graduação em Educação. Universidade Estadual de Maringá. Maringá: 2006. (Apêndice C).

SANTA CATHARINA. Annaes da $1^{a}$ Conferência Estadual do Ensino Primário. 31 de julho de 1927. Florianópolis, Off. Graph. da Escola de Aprendizes de Artífices, 1927b.

SANTA CATHARINA. Regimento Interno da Conferência de Ensino Primário. Gabinete da Imprensa Official. Florianópolis, 1927a.

SILVA, J. A. P. Carneiro Leão e a proposta de organização da educação popular brasileira no início do século XX. 131 f. Dissertação (Mestrado em Educação). Programa de Pós-Graduação em Educação.Universidade Estadual de Maringá. Maringá, 2006.

SIRINELLI, J. F. As elites culturais. In: RIOUX, J. P.; SIRINELLI, J. (dirs.). Para uma história cultural. Traduzido por Ana Moura. Lisboa: Editorial Estampa, 1998. p. 349-363.

SIRINELLI, J. F. Histoire des droites em France. v. 2, Cultures, Paris: Gallimard, 1992, p. III-IV

SIRINELLI, J. F. Intellectuels et passions françaises: manifestes et petitions au XXe. siecle. (França): Fayard, 1990.

SIRINELLI, J. F. Le hasard ou la nécessité? Une histoire en chantier: l'histoire des intellectuels. In: Vingtième Siècle. Revue d'histoire. n. 9, p. 97-108, janvier-mars, 1986.

SIRINELLI, J. F. Os intelectuais. In: RÉMOND, R. Por uma história cultural. 2. ed. Rio de Janeiro: Editora FGV, 2003. p. 231-269.

SOUZA, G.; ANJOS, J. J. T. A criança, os ingênuos e o ensino obrigatório no Paraná. In. VIDAL, D. G.; SÁ, E. F.; SILVA, V. L. G. (Orgs.). Obrigatoriedade escolar no Brasil. Cuiabá: EduFMT, 2013. p. $189-208$.

TILLY, C. Coerção, capital e Estados europeus. São Paulo: Edusp, 1996. (Col. Clássicos).

TILLY, C. Contentions repertoires in Great Britain, 1758-1834. Social Science History, 17: 2, Supplied by The British Library, 1993. p. 253-280. 
TILLY, C. Getting together in Burgundy (1675-1975). CRSO Working Paper U128, Center for Research on Social Organization, Universidad de Michigam, maio, 1976.

TILLY, C. Itinerários em análise social. Tempo Social, São Paulo, v. 16, n. 2, p. 299-302, 2004.

TILLY, C. McADAM, D.; TARRROW, S. Para mapear o confronto político. Trad. Ana Maria Sallum. Lua Nova, São Paulo, n. 76, p. 11-48, 2009.

TILLY, C. Contentious repertoires in Great Britain, 1758-1834. In: Traugott, Mark (org.). Repertoires and cycles of collective action. Durham, NC: Duke University Press, 1995, p. 15-42.

VIEIRA, A. L.; FARIAS, I. M. S. (Orgs.). Documentos de política educacional no Ceará: Império e República. Colaboração: NOGUEIRA, D. L. et al. Brasília: Instituto Nacional de Estudos e Pesquisas Educacionais Anísio Teixeira, 2006. (Col. Documentos da Educação Brasileira).

Submetido: $29 / 08 / 2020$

Aprovado: 05/10/2020 